\title{
Uso preventivo de virginiamicina mitiga acidose láctica ruminal em bovinos Nelore
}

Francisco Leonardo Costa de Oliveira[a]", Rejane Santos Sousa ${ }^{[a]}$, Juliana Aparecida Alves dos Santos[ ${ }^{[a]}$, Carolina Akiko Sato Cabral de Araújojo ${ }^{[b]}$, Christopher Roger White ${ }^{[c]}$, Bruno Honda ${ }^{[c]}$, Luís Felipe Prada e Silva ${ }^{\left[{ }^{[a]}\right.}$, Alexandre Vaz Pires ${ }^{[a]}$, Ives Cláudio da Silva Bueno $0^{[a]}$, Enrico Lippi Ortolani[a]

\footnotetext{
[a] Universidade de São Paulo (USP), São Paulo, SP, Brasil

${ }^{[b]}$ Faculdade de Medicina Veterinária, Universidade Federal Rural de Pernambuco (UFRPE), Recife, PE, Brasil

[c] Phibro Saúde Animal, Guarulhos, SP, Brasil
}

*Autor correspondente

e-mail: oliveiraflc@usp.br

\section{Resumo}

O confinamento de bovinos de corte é uma das principais estratégias para o aumento da produtividade nesse segmento. A adoção de dietas ricas em energia predispõe o surgimento de quadros de acidose ruminal, sendo esta a segunda principal enfermidade nessa prática. As medidas preventivas são baseadas no manejo nutricional adequado e no uso de aditivos dietéticos, que interferem no crescimento de bactérias que produzem os ácidos mais fortes no rúmen (Streptococcus bovis e Lactobacillus sp.) ou que estimulam as bactérias lactilíticas que transformam ácido láctico (forte) em ácido propiônico (mais fraco). Entre os aditivos destaca-se a virginiamicina (VM). 0 presente estudo avaliou comparativamente a eficácia de diferentes doses de virginiaminina na prevenção da acidose láctica ruminal (ALR) induzida em bovinos. Para tal, foram utilizadas 18 fêmeas bovinas, da raça Nelore, providas de cânula ruminal, com cerca de 300 kg de PC, que recebiam antes da indução, dieta calculada em 2,7\% do PC composta de 75\% da matéria seca de feno de coast-cross e de $25 \%$ de concentrado. Os animais foram distribuídos aleatoriamente em função do peso em três grupos com seis animais cada, assim constituídos: controle (C), virginiamicina 25 ppm (VM25), virginiamicina 34 ppm (VM34). 0 antibiótico foi administrado em conjunto com fubá de milho por um período de 30 dias antes da indução de ALR. Essa indução foi feita por meio da administração de sacarose no rúmen, de acordo com protocolo clássico, levando-se em consideração a seguinte formula y = $1053+43,1$ x PV 00,75 . Foram realizadas coletas de amostras de fluído ruminal nos seguintes momentos: zero (basal) e após três, seis, 12 e 18 h da indução. As seguintes variáveis ruminais foram avaliadas: pH, lactato L, acidez titulável e propionato. Foi realizada análise de variância de medidas repetidas no tempo de duas vias, considerando os fatores grupo e momento, seguido de teste de comparação de média de Bonferroni. Os dados obtidos no 
pico da ALR (18 ${ }^{\circ} \mathrm{h}$ ) no grupo C (pH 4,04; $71 \mathrm{mM}$ de lactato-L e $81 \mathrm{UC}$ ) indicam que ocorreu uma acidose de grau intenso, causada principalmente por excesso de lactato. Em relação ao grupo C pode-se afirmar que: as duas doses de VM aumentaram o pH ruminal ( $\mathrm{P}=0,019$ ); o VM25 diminuiu os teores de lactato na ordem de 14,4\%; e o VM34 gerou menor acidez titulável ( $\mathrm{P}=0,0015)$, na ordem de 19,8\%. Os menores teores de lactato no grupo VM25 foram obtidos pela transformação deste ácido em ácido propiônico $(\mathrm{R} 2=0,57)$. Conclui-se que a adição de virginiamicina mitiga quadros de ALR intensa em bovinos de corte. 